\title{
Radical Formation Initiates Solvent-Dependent Unfolding and $\beta$-sheet Formation in a Model Helical Peptide
}

\author{
Michael C. Owen, ${ }^{\mathrm{a}^{*}}$ Birgit Strodel, ${ }^{\mathrm{a}, \mathrm{b}}$ Imre G. Csizmadia, ${ }^{\mathrm{c}, \mathrm{d}, \mathrm{e}}$ and Béla Viskolcz ${ }^{\mathrm{d}, \mathrm{e}}$ \\ ${ }^{a}$ Institute of Complex Systems: Structural Biochemistry (ICS-6) Forschungszentrum Jülich, 52425 Jülich, Germany \\ ${ }^{b}$ Institute of Theoretical and Computational Chemistry, Heinrich Heine University Düsseldorf, Universitätsstrasse 1, 40225 \\ Düsseldorf, Germany \\ 'Department of Chemistry, University of Toronto, Toronto, ON Canada M5S 3H6 \\ ${ }^{d}$ Institute of Chemistry, Faculty of Material Science, University of Miskolc, Egyetemváros 1, H-3529 Miskolc, Hungary \\ ${ }^{\mathrm{e}}$ Drug Discovery Research Center (www.drugcent.eu) \\ *Corresponding author: m.owen@fz-juelich.de Phone: (+49-2461-61-9486)
}

\section{SUPPORTING INFORMATION}


Table S1. The number of clusters and the population of the structures in the largest cluster found in the cluster analysis of the 50 ns extension of Run 1. The RMSD of the central structure of the largest cluster of Run 1 of each system was compared to that of the results of the analysis of all three $100 \mathrm{~ns}$ runs.

\begin{tabular}{|c|c|c|c|c|}
\hline $\begin{array}{l}\text { Solvent of } \\
\text { System }\end{array}$ & Peptide & $\begin{array}{l}\text { Number of } \\
\text { Clusters }\end{array}$ & $\begin{array}{c}\text { Proportion of } \\
\text { Structures in Most } \\
\text { Populated Cluster / \% }\end{array}$ & $\begin{array}{c}\text { RMSD from first } 100 \\
\text { ns }(\AA)\end{array}$ \\
\hline $100 \% \mathrm{H}_{2} 0$, & AL10 & 371 & 9.4 & 5.43 \\
\hline $0 \%$ TFE & AL10(R) & 460 & 8.8 & 3.91 \\
\hline $80 \% \mathrm{H}_{2} \mathrm{O}$ & AL10 & 744 & 3.1 & 1.89 \\
\hline $20 \% \mathrm{TFE}$ & AL10R & 1692 & 1.0 & 4.44 \\
\hline $60 \% \mathrm{H}_{2} 0$ & AL10 & 1319 & 1.0 & 4.23 \\
\hline $40 \% \mathrm{TFE}$ & AL10R & 2242 & 0.3 & 5.78 \\
\hline $40 \% \mathrm{H}_{2} \mathrm{O}$ & AL10 & 533 & 5.3 & 0.76 \\
\hline $60 \% \mathrm{TFE}$ & AL10R & 1163 & 0.8 & 4.69 \\
\hline $20 \% \mathrm{H}_{2} 0$ & AL10 & 589 & 7.4 & 0.81 \\
\hline $80 \%$ TFE & AL10R & 419 & 11.8 & 0.55 \\
\hline $0 \% \mathrm{H}_{2} \mathrm{O}$ & AL10 & 198 & 32.7 & 0.43 \\
\hline 100\% TFE & AL10R & 340 & 9.9 & 0.48 \\
\hline
\end{tabular}


A
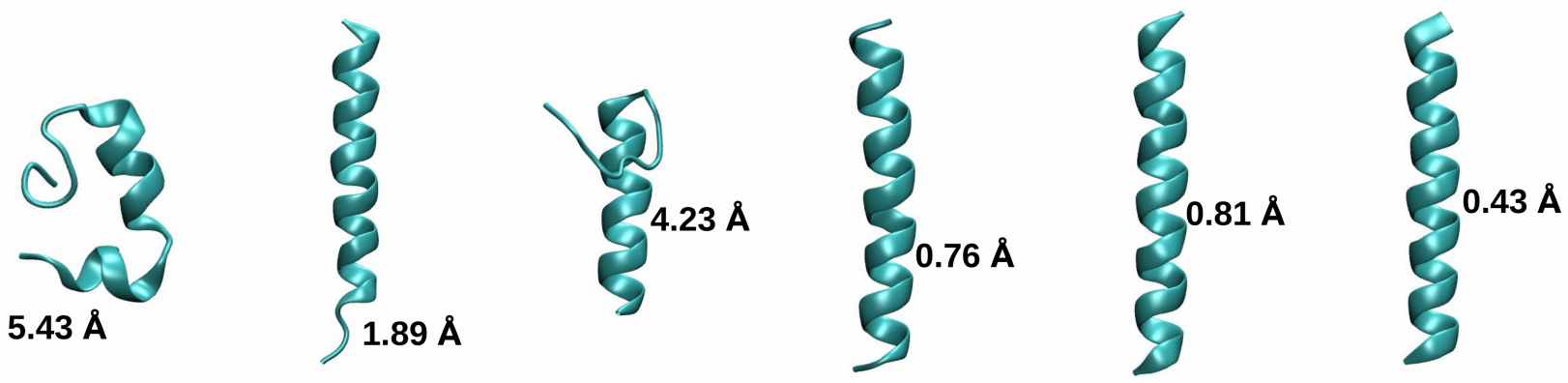

B
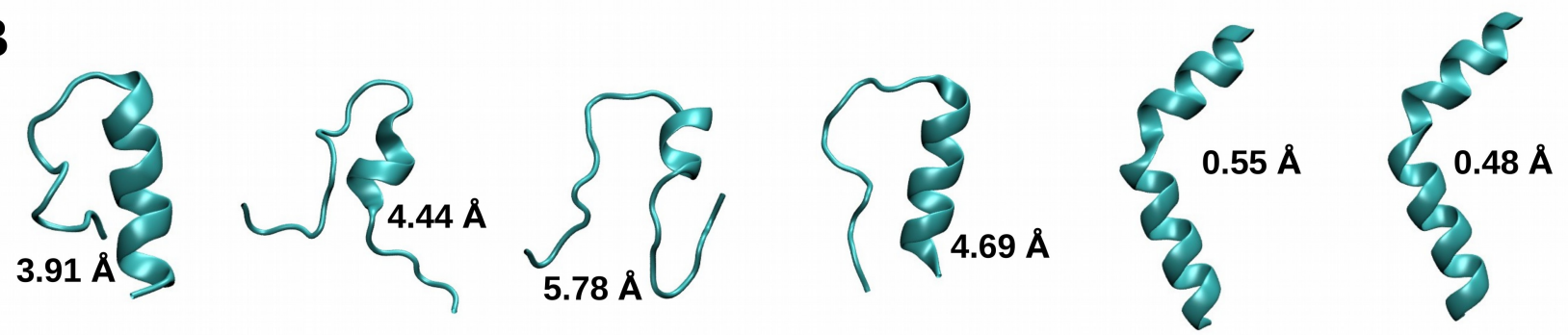

$100 \%$ Water,

$80 \%$ Water, $20 \%$ TFE

$60 \%$ Water,

40\% Water, $60 \%$ TFE

$20 \%$ Water, $80 \%$ TFE
$0 \%$ Water, $100 \%$ TFE

Figure S1. The central cluster of the largest cluster of the AL10 (A) and AL10(R) (B) structures shown in Table S1. 

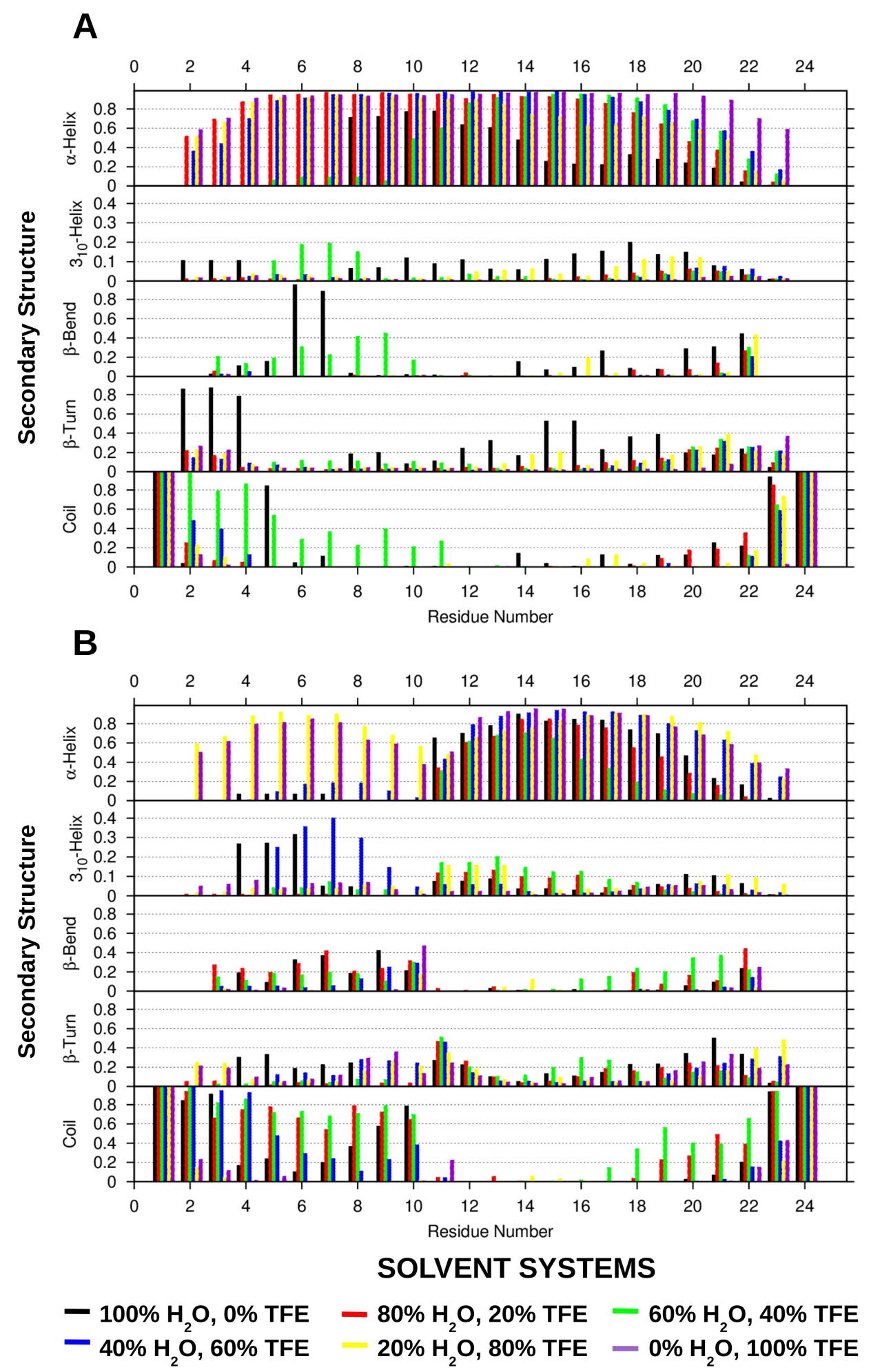

Figure S2. The DSSP of the AL10 (A) and AL10(R) (B) runs described in Table S1. 


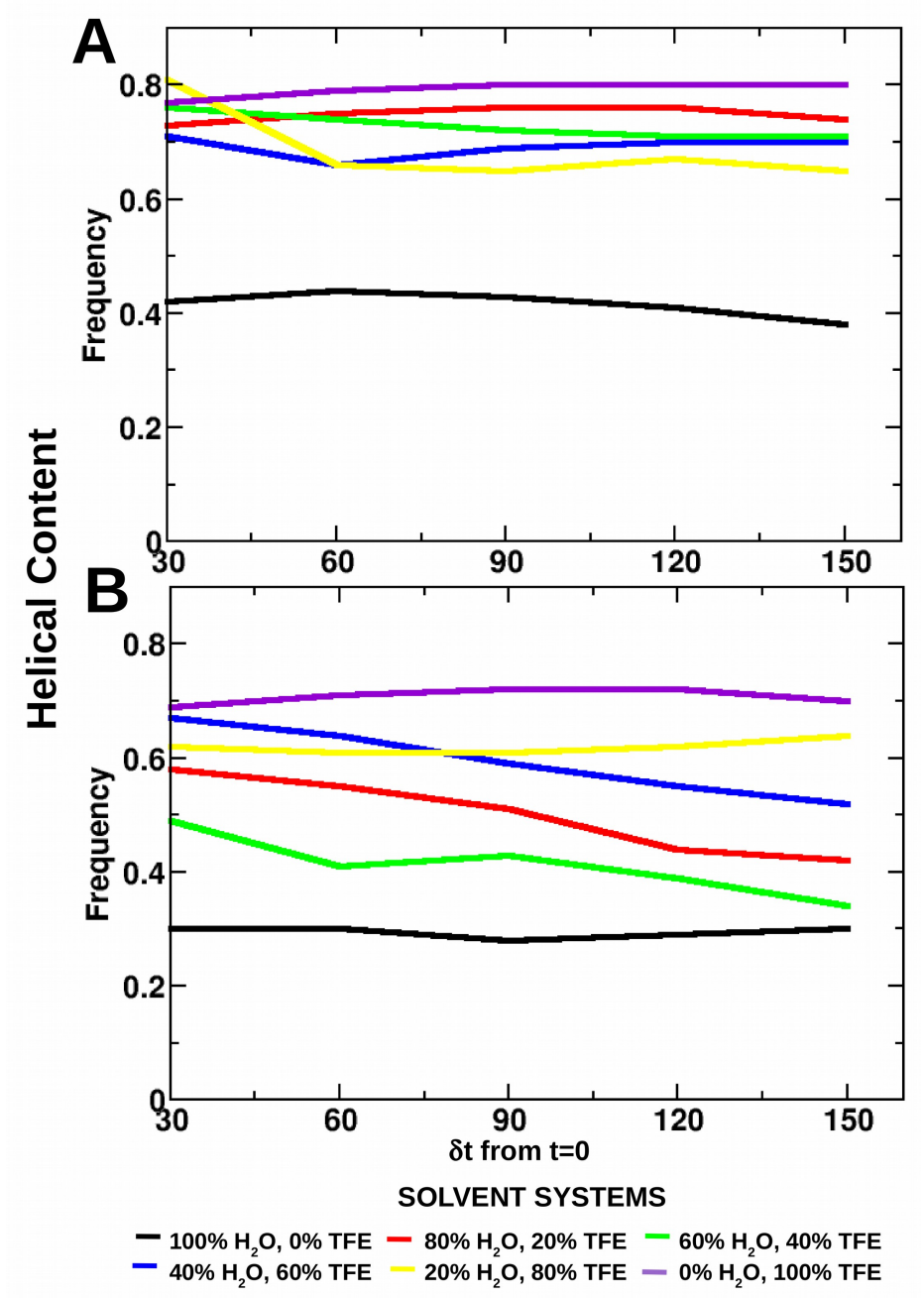

Figure S3. The results of the convergence test in which the $\alpha$-helical content during incremental intervals from $\mathrm{t}=0$ was measured using the DSSP method. The helical drift of AL10, is shown in panel A, whereas the helical drift of AL10(R) is shown in B. The largest drift in AL10 was a 15\% decrease in the helical content in $80 \%$ TFE, whereas a decrease of about $10 \%$ was shown by AL10(R) in $20 \%-60 \%$ TFE. The DSSP method showed the highest helical content for AL10 in 100\% TFE, whereas the i, i+4 hydrogen bonding indicated that AL10 had the highest helicity in 20\% TFE. The helicity in the other systems remained constant and the modest drift shown in the aforementioned systems does not affect the conclusions of this study. 